Article

\title{
Fine-Scale Evaluation of Giant Panda Habitats and Countermeasures against the Future Impacts of Climate Change and Human Disturbance (2015-2050): A Case Study in Ya'an, China
}

\author{
Jing Zhen ${ }^{1,2}$, Xinyuan Wang ${ }^{1}$, Qingkai Meng ${ }^{3}$, Jingwei Song ${ }^{4}$, Ying Liao ${ }^{5}$, Bo Xiang ${ }^{1}$, \\ Huadong Guo ${ }^{1}$, Chuansheng Liu ${ }^{1}$, Ruixia Yang ${ }^{1}$ and Lei Luo ${ }^{1, *}$ \\ 1 Institute of Remote Sensing and Digital Earth, Chinese Academy of Sciences, Beijing 100094, China; \\ zhenjing@radi.ac.cn (J.Z.); wangxy@radi.ac.cn (X.W.); xiangbo@radi.ac.cn (B.X.); hdguo@radi.ac.cn (H.G.); \\ liucs@radi.ac.cn (C.L.); yangrx@radi.ac.cn (R.Y.) \\ 2 College of Resources and Environment, University of Chinese Academy of Sciences, Beijing 100049, China \\ 3 State Key Laboratory of Plateau Ecology and Agriculture, Qinghai University, Xining 810016, China; \\ mengqk@cdut.edu.cn \\ 4 Centre for Autonomous Systems, University of Technology Sydney, Ultimo, NSW 2007, Australia; \\ jingwei.song@student.uts.edu.au \\ 5 Technology and Engineering Center for Space Utilization, Chinese Academy of Sciences, Beijing 100094, \\ China; liaoying@csu.ac.cn \\ * Correspondence: luolei@radi.ac.cn; Tel.: +86-10-8217-8128
}

Received: 22 March 2018; Accepted: 3 April 2018; Published: 4 April 2018

\begin{abstract}
The accelerating impact of climate change on giant panda (Ailuropoda melanoleuca) habitats have become an international research topic. Recently, many studies have also focused on medium-sized mountain ranges or entire giant panda habitats to predict how habitats will change as the climate warms, but few say in detail what to do or where to focus efforts. To fill this gap, this paper presents a new method to take comprehensive, fine-scale evaluations incorporating climate change, human disturbance, and current conservation networks and translate them into practical countermeasures in order to help decision-makers set priority regions for conservation. This study looked at the core area of the Sichuan Giant Panda Sanctuaries United Nations Educational, Scientific and Cultural Organisation (UNESCO) World Natural Heritage site, namely Ya'an Prefecture, as a case study. The research employs the Maximum Entropy (MaxEnt) modeling algorithm to analyze how climate change will affect the habitats by 2050 under two scenarios: only considering the influence of climate change, and thinking about the coupled influence of climate change and human disturbance together. The results showed the following: (1) only considering climate change, the overall habitat that can be used by giant pandas in this region will increase, which differs from most of the previous results showing a decrease; (2) the new suitable habitat will shift westward, northward and eastward in this region; (3) conversely, the suitable habitat will be significantly reduced (about 58.56\%) and fragmentized when taking into account human disturbance factors; (4) at present, the three small nature reserves are far from each other and cannot cover the present habitat well nor protect the potentially suitable habitats. Based on the comprehensive analysis of habitat shifts and our two field investigations, we suggest two regions that can be expanded into the conservation network to contain more potentially suitable habitats in the future. Furthermore, we used a geographical information system to incorporate high-resolution remote-sensing images from the GF-1 satellite, land-cover maps, and a digital elevation model (DEM) to verify the possibility of our two suggested regions.
\end{abstract}

Keywords: climate change; habitat evaluation; MaxEnt; geographic information system; giant panda; species distribution modeling 


\section{Introduction}

Rapid climate change is threatening global ecosystems and biodiversity by affecting certain species and the surrounding environments they depend on [1-3]. Climate change together with other stressors adversely affects habitats which, in turn, can lead to changes in species distribution, community composition, phenology and ecosystem functions [4,5], particularly for species characterized by a limited habitat, small population, low reproductivity, and weak migration ability. These species have poor tolerance to environmental changes and face the risk of extinction [6,7]. Unfortunately, it has been reported that the risk of extinction will be accelerated by future global warming. It was estimated that, in the current situation, one in four mammalian species are threatened with extinction and one in two is declining globally [8].

The giant panda (Ailuropoda melanoleuca) is one of the most widely recognized threatened mammals and was categorized as Endangered on the International Union for Conservation of Nature (IUCN) Red List in 1988 [9,10]. The species was once widespread throughout southern China, as far north as Beijing and south into south-east Asia during the 16th to 19th centuries, but in the past several hundred years the population and distribution range have both decreased dramatically due to the combined adverse effects of climate change, geological vicissitudes and human activities [11]. The rapid growth of the human population and climate warming over the past 300 years have resulted in much of the under-forest bamboo, which is the panda's principal source of food, being replaced by farmland. Consequently, the giant panda is now confined to six isolated mountains located in Sichuan, Shaanxi and Gansu provinces in south-central China [12,13]. High mountain ecosystems are considered to react sensitively to climate warming and express profound impacts [14,15]. In addition, the living situation of the giant panda became even worse because of its biological constraints, including dietary specialization ( $99 \%$ of the food comes from bamboo) [16], low reproductive rates, and restricted gene flow [17]. At the same time, habitat fragmentation has worsened. For example, giant panda populations were divided into about 24 local populations in the early 1990s [18], but now this number has increased to 33, of which 24 face a high risk of extinction (including 233 giant pandas, accounting for about $12 \%$ of the total population) $[19,20]$. Furthermore, it has long been recognized that despite the slow and gradual climate variability, rapid climate changes might be expected, since the climate system is in an unstable equilibrium. In this context, Varotsos et al. (2014) found that the increase in sea-surface temperature over $30^{\circ} \mathrm{S}-60^{\circ} \mathrm{N}$ from 1900 to 2012 did not occur slowly and gradually, but abruptly in 1925/1926 and 1987/1988 with events time-separated by 62 years, i.e., an interval reminiscent of the well-established quasi 60-year natural cycle [21]. Evidence for the quasi 60-year oscillation has also been found by Zhen-Shan and Xian (2007) and has been shown to be among the most prominent climate variability components of the annual mean temperature in China, the Northern Hemisphere, and globally in the period from 1881 to 2002 [22]. Meanwhile, under-forest bamboo, the main food for giant pandas, has also shown a reproduction cycle of 50-100 years through mass flowering. For example, the Fargesia spathacea mass flowering from 1975-1976 in Minshan Mountain caused the death of nearly 150 giant pandas [23]. All these factors mean the giant panda faces severe challenges to its survival.

Detailed and reliable information about the adverse effect of future climate change on giant panda habitats is necessary and urgent. Therefore, the responses of habitats to climate change attract substantial attention from researchers. However, most efforts are at medium or large scales. e.g., the studies have focused on the whole distribution range [24,25] or on mountain ranges, such as the Qinling Mountains [26-28], the Minshan Mountains [16,29] and the Daxiangling Mountains [30]. This is problematic because the results are difficult to translate into viable decisions. In addition, previous studies have often predicted the direction of habitat shifts in the context of a changing climate, and calculated the change rate $[7,27]$. However, there is a lack of work focusing on local regions putting forward possible specific measures based on current protection networks, which is among the most compelling challenges to conservation efforts in protecting species' persistence [16]. At the same time, data in previous studies associating the giant panda's presence with environmental issues have often 
been based on the results of the Third National Giant Panda Survey (1999-2003), which was completed more than 10 years ago and needs to be updated with the most recent survey data.

To address these issues and, considering our group's previous research work [31], we chose the case study of the giant panda in the core area of the Sichuan Giant Panda Sanctuaries United Nations Educational, Scientific and Cultural Organisation (UNESCO) World Natural Heritage site, in Ya'an Prefecture located in the middle of Sichuan Province, China. We used a maximum entropy (MaxEnt) model together with the latest ground survey data, i.e., the Fourth National Giant Panda Survey (2011-2014) and the most recent Intergovernmental Panel on Climate Change-Coupled Model Intercomparison Project Phase 5 (IPCC-CMIP5) climate scenarios to forecast the probability of changes in the distribution and quality of giant panda habitats by 2050. Shifting geographic ranges are likely to have profound consequences for the effectiveness of the protected area networks. Therefore, we also incorporated the distribution shift's results with the current conservation network to clarify key areas and strategies for future conservation planning. Through this new analytical method, we aimed to provide a reference for conservation management of this species. Meanwhile, we expect this approach to be promising in predicting the potential distribution of other similar species confined elsewhere in fringe ecological patches.

\section{Study Area}

Ya'an is regarded as the "hometown of giant pandas" because this is where the first giant panda was found by French Jesuit Armand David in 1869 [32]. Ya'an is the core area of the Sichuan Giant Panda Sanctuaries World Natural Heritage site, which constitutes the largest remaining contiguous habitat of the giant panda. At the same time, this area belongs to the transition zone from the Sichuan Basin to the Qinghai-Tibet Plateau and the connection zone between the Qionglai Mountains and Daxiangling Mountains, which are two of the six isolated mountains where giant pandas still exists.

According to the latest fourth survey report on giant pandas (2011-2014) [33], the total giant panda habitat within Ya'an Prefecture is 547,700 ha, accounting for 21.3\% of the whole giant panda habitat and ranking Ya'an as the city in China with the largest habitat area. Meanwhile, more than 340 wild giant pandas live in this area, or $18.24 \%$ of the total number of wild pandas in China. Compared to the third survey data (1999-2003), the number and density of wild giant pandas have both increased. In this paper, we focus on the areas inhabited by wild pandas with substantial investigation records including Baoxing, Tianquan, Lushan and Yingjing counties. The study area $\left(102^{\circ} 15^{\prime} \sim 103^{\circ} 23^{\prime} \mathrm{E}\right.$, $29^{\circ} 28^{\prime} \sim 30^{\circ} 56^{\prime} \mathrm{N}$ ) holds 315 wild giant pandas, accounting for $92.65 \%$ of the total panda population in Ya'an. Currently, there are three nature reserves within our study area, the Fengtong national nature reserve, the Labahe provincial nature reserve, and the Daxiangling provincial nature reserve. The elevation ranges from $557 \mathrm{~m}$ to $5290 \mathrm{~m}$ in this region, with the higher elevations found mainly in the northern and western parts of the region while lower elevation is found in the east. The climate type is classified as a subtropical monsoon humid climate and the mean annual temperature ranges from $14.1^{\circ} \mathrm{C}$ to $17.9^{\circ} \mathrm{C}$. The annual rainfall is often more than $1000 \mathrm{~mm}$ and the average humidity is more than $80 \%$. Therefore, in most cases, the study area was covered by cloud and fog, which made acquiring high-quality optical remote-sensing images difficult. The location of the study area can be seen in Figure 1. 


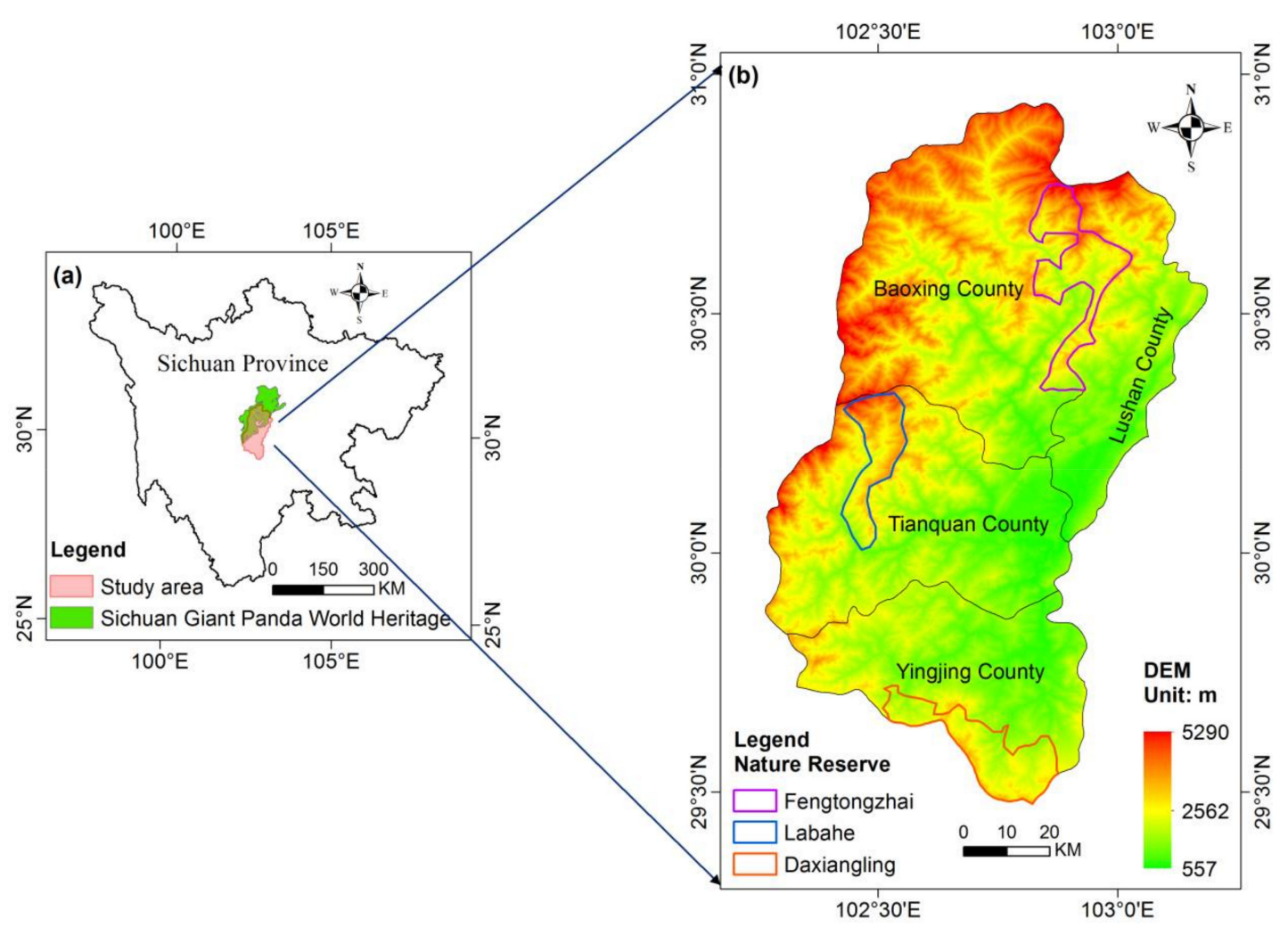

Figure 1. (a) The location of Ya'an Prefecture in Sichuan Province, the study area covering the core region of the Sichuan Giant Panda Sanctuaries World Natural Heritage site; (b) the digital elevation model (DEM) of the study area covering Baoxing, Lushan, Tianquan and Yingjing counties, and the three nature reserves within the study area.

\section{Materials and Methods}

\subsection{Data Sources}

The evaluation of the species and the environment where the species resides is an important method for analyzing reasons for the species' population reduction and the causes of endangerment, as well as providing the basic information for formulating reasonable protection measures. Based on the long-term accumulation of research on the biology and ecology of giant pandas, researchers classified the factors influencing giant panda survival and reproduction as three types, namely physical environmental factors, biological factors and human disturbance factors [34,35]. Recently, with accelerated climate change, the influence of climate factors on biodiversity worldwide has increased dramatically. Therefore, through comprehensive analysis of previous studies, we divided the factors affecting giant panda habitats into four types: physical environment factors, biological factors, human disturbance factors, and bioclimatic factors [17,29,31,36-38]. In this study, elevation, slope and aspect were employed as physical environment factors. The distribution of the bamboo and the distance to drainage were used as biological factors. The human disturbance factors included roads, mines, hydropower stations, power transmission lines and scenic spots. Bioclimatic factors consisted of 19 climatic variables obtained from WorldClim (http:/ / www.worldclim.org/), including annual mean temperature, maximum temperature of warmest month, annual precipitation, and precipitation of wettest quarter, among others. In total, there were six kinds of data used in this study.

\subsubsection{Physical Environmental Data}

According to the field survey data and related research, the giant pandas in Wolong nature reserve, which is near our study area at Qionglai Mountain, were often found in areas where the elevation 
ranges from $1400 \mathrm{~m}$ to $3600 \mathrm{~m}$, with flat ridges and gentle slopes below 20 degrees [34]. In addition, giant pandas currently remain in bamboo-forest habitats across six isolated mountain ranges where the vertical zonality of vegetation is obvious (different vegetation types change with elevation). Therefore, we chose elevation, slope and aspect as physical environmental factors. A digital elevation model (DEM) is a grid-based model that simulates ground elevation. The DEM data in this study were produced by NASA (the National Aeronautics and Space Administration) and METI (the Ministry of Economy, Trade and Industry). The data have a resolution of $30 \mathrm{~m}$, a vertical precision of $20 \mathrm{~m}$ and horizontal accuracy of $30 \mathrm{~m}$. Slope and aspect were derived from DEM data.

\subsubsection{Biological Factor Data}

The giant panda was once a large carnivorous or omnivorous animal. In order to survive, after millions of years of evolution and adaptation to environmental change, it gradually evolved into a specialized dietary species; $99 \%$ of its diet now consists of understory bamboos $[39,40]$. So bamboo distribution has a strong relationship with habitat suitability. The spatial distribution of bamboo was derived from the third and fourth national surveys for giant pandas. Also, the giant panda shows a strong preference for flowing drinking water. Areas with many small rivers or nearby drainage are preferred by giant pandas. If there is a rich abundance of food to eat, but no water, it is difficult to find traces of panda activity [41]. Therefore, our study used the distance to drainage as a biological factor. The drainage data were obtained mainly from the Chinese National Basic Geographic Information Database, supplemented by the interpretation of remote-sensing images and field survey data. The distance from the water source was calculated using ArcGIS 10.2.

\subsubsection{Human Disturbance Data}

Worldwide, habitat loss due to degradation and harvesting (hunting or gathering for food, medicine, fuel, and materials) is by far the main threat to mammals [42]. As for giant pandas, human disturbance is known to intensify the negative impacts of climate change through habitat loss and fragmentation [7]. According to the survey report, the giant panda can be affected by more than 20 factors, such as logging, hunting, grazing, road construction, hydropower stations, and power transmission lines [11,33]. Significantly decreased forest area resulted in the massive loss and fragmentation of the giant panda habitat. From the beginning of the 1970s to the middle of the 1980s, the habitat of the giant panda decreased by more than $56 \%$ [43]. Road construction also led to habitat fragmentation, hindering and reducing genetic exchanges between populations, which may eventually lead to habitat loss [44,45]. Mineral and bamboo resources are rich in Ya'an, hence human activities such as mining and cutting bamboo often occurred within our study area, which was one of the main interference factors affecting giant panda habitats. According to the fourth giant panda survey report [33], we selected five kinds of human disturbances encountered frequently in the study area for our analysis: roads, hydropower stations, scenic spots, mines and power-transmission lines.

\subsubsection{Bioclimatic Data}

The climate data in this study were derived from the WorldClim website (http: / / www.worldclim.org). In total, 19 bioclimatic variables based on the BCC-CSM1-1 GCM (Global Climate Model) under the RCP (Representative Concentration Pathway) 4.5 emission scenario were obtained for current and future analysis, up to 2050 . The spatial resolution of the data is 30 arc-seconds $(\sim 1 \mathrm{~km})$. WorldClim data are produced by interpolation based on the meteorological information records (1950-2000 average) from the world's weather stations [46]. At the same time, a climate system model is an important tool for studying the mechanisms for past climate change and to project future climate change. In this paper, we chose BCC-CSM1-1 as our GCM model because this model is used to carry out most of the CMIP5 experiments and performs well in simulating the historical evolution of the surface air temperature, globally and averaged for China [47]. In addition, the model was also selected by the China National Climate Impact Assessment Report because its results were robust, with high 
reliability [16]. The implications of climate change for the environment and society will depend not only on the response of the Earth system to changes in radiative forcings, but also on how humankind responds through changes in technology, economies, lifestyle and policy [48]. The latest representative concentration pathways (RCP) released by IPCC include four different levels, RCP 2.6, 4.5, 6.0, and 8.5, with radiative forcing increasing gradually. We selected the mid-range RCP 4.5 as the future climate emission scenario based on comprehensive consideration of the development trend of China and its conservation efforts.

In addition to these, we also obtained the temperature and precipitation records in the study area from 1951-2016 from the China Meteorological Data Service Center (CMDC, http:/ / data.cma.cn) to analyze the climate change trend and rate of giant panda habitat change.

\subsubsection{Remote-Sensing Data}

The optical remote sensing data in the Sichuan Basin usually have poor quality due to abundant rainfall and clouds. To coincide with the times of the third (1999-2003) and fourth (2011-2014) giant panda ground surveys directed by the National Forestry Administration, we selected Landsat data from 13 June 2001, and 19 July 2011. Both dates had minimal cloud cover and could be utilized for land-use and land-cover change (LUCC) detection between the two ground surveys. GF-1 satellite images with 16-m resolution were acquired to validate the classification results and to check the feasibility of the suggested new reserve regions.

\subsubsection{Ground Investigation Data}

Signs of pandas such as droppings, feeding remnants, and footprints were used as the sample data in the MaxEnt model, as well as both the human disturbance factors (roads, hydropower stations, scenic spots, power-transmission lines) and the nature reserve boundary derived from the fourth giant panda survey.

In addition, the research team carried out two field investigations to assess human disturbance factors, verify the vegetation-type classification, and verify the accuracy of the panda habitat suitability assessment. The first field investigation was executed from June to July 2013 just after the Ya'an earthquake, which occurred on 20 April 2013. The epicenter was located in Lushan County, Ya'an, Sichuan, about $116 \mathrm{~km}$ from Chengdu along the Longmenshan fault in the same province heavily impacted by the 2008 Sichuan earthquake. Therefore, we focused mainly on the Wolong, Caopo and Fengtongzhai nature reserves to assess the influence of the two earthquakes on the giant panda's habitat alongside the tasks mentioned above. We finished the second field investigation on 7-13 June 2014, undertaking similar investigative work. At that time, we started from Chengdu, then passed by Dujiangyan, Yingxiu, Gengda and Wolong. We then crossed Balang Mountain and Jiajin Mountain and arrived at Fengtongzhai nature reserve, after which we went to Baoxing County, Lushan County, Ya'an city, then back to Chengdu. Based on the ground investigation data from this field work, our research group has already published papers related to giant pandas [31,49-51].

All of the data were converted to the UTM WGS84 coordinate system. Our research area is within a remote, high-elevation region where the spatial resolution of the climate observation network ranges from tens to hundreds of kilometers; therefore, the raster data were unified to the same resolution of $1 \mathrm{~km} \times 1 \mathrm{~km}$ to match the resolution of gridded climate data downloaded from the WorldClim website.

\subsection{Research Method}

Species distribution models (SDMs) are commonly used to predict the geographic range of a species given presence-only occurrence data and environmental variables assumed to influence its distribution [3,52,53]. One SDM, the MaxEnt algorithm, has proven powerful when modeling rare species with narrow ranges and scarce presence-only occurrence data [54,55]. This model is widely used in endangered species protection, protected area planning, invasive species control, and climate change impacts on the distribution of biological areas $[7,16,26,27,29,56,57]$. Therefore, we used MaxEnt 
(version 3.3.3k) in this study to model environmental suitability for giant pandas under RCP 4.5 in the year 2050.

MaxEnt estimates a species' distribution by finding the probability distribution of maximum entropy (i.e., the mean of each variable in the projected distribution is close to means of the observed data) subject to the constraints of where data are actually available. The basic idea of this model is to predict species distribution by maximizing entropy based on presence data and derived environmental variables calculated by the following formula:

$$
q \lambda(x)=e^{\lambda \cdot f(x)} / Z_{\lambda}
$$

where $\lambda$ is a vector of $\mathrm{n}$ real value coefficients or feature weights, $f$ is the vector of all environmental factors, and $Z_{\lambda}$ is a normalizing constant that ensures the $q$ value sums to 1 . First, we built the distribution layer of likely giant panda habitats and identified corresponding environmental factors in the study area. Subsequently, when a pixel had environmental conditions equal to the training data, higher values were assigned to this pixel, and vice versa. The likelihood of presence of each pixel was calculated by iteration, whereby a variable was omitted and the remaining variables were used to build the model until minimal presence was available. Linear, quadratic, product and hinge functions of the environmental variables were selected for inclusion in the model, and the convergence threshold was set to 10-6. Finally, two suitability maps were created for the present and for 2050 by selecting $75 \%$ of the total 313 presence data $(n=235)$ and 10,000 random background pixels (treated as negative instance) as training data, and the remaining $25 \%$ of presence data (about 78 ) were used for testing the model.

A habitat suitability index (HSI) was used to reflect high and low habitat suitability for pandas. HSI values ranged from 0 to 1 , where 0 is an extremely unsuitable habitat, and 1 is the most suitable habitat $[54,58]$. A detailed flowchart is shown in Figure 2. It should be noted that this method assumes that presence data are not biased and that environmental conditions are uniformly sampled [59]. To evaluate the accuracy of the MaxEnt model, receiver operating characteristic (ROC) analysis was adopted. The area under the ROC function (AUC) is a performance index widely used as an indicator of a model's ability to discriminate between suitable and unsuitable habitats [60]. An AUC close to 1 indicates a more ideal model. Models with AUC greater than 0.7 are considered to achieve acceptable performance [61].

In order to undertake this fine-scale evaluation, first we acquired six kinds of data: the giant panda sample data and the human disturbance data both from the fourth survey on giant pandas (2011-2014), the physical environmental data (elevation, slope and aspect), the biological factor data (bamboo distribution map and the map of distance to drainage), the 19 bioclimatic variables, and different sources of remote-sensing data. Then we preprocessed the data for the MaxEnt model. Special attention was given to resampling all the raster data to the same resolution because the MaxEnt model is inefficient in dealing with data acquired from different sampling methods [54]. Furthermore, the selection of predictor variables that capture environmental influences on species distributions is very important in SDM modeling. When incorporating multiple sources of information to SDM, the inclusion of biologically meaningful variables that directly relate to demographic rates and the exclusion of "relaxed" variables or variables that have little importance should be considered [62]. To minimize the bioclimatic variables' collinearity and their impact on the following analyses, we used the correlation/variable contribution (CVC) approach [62]. Firstly, we ran the model and eliminated the variable if its contribution $\leq 1 \%$, then we evaluated the inter-correlations among the 19 bioclimatic variables. If two variables were highly correlated, we retained the variable contributing most to model accuracy gain and eliminated the second variable, then we retained a subset of uncorrelated $(|\gamma|<0.7)$ variables. In this paper, we used 8 (out of 19) bioclimatic variables in modeling the habitat suitability, including mean diurnal range (bio2), isothermality (bio3), temperature seasonality (bio4), maximum temperature of the warmest month (bio5), annual temperature range (bio7), annual precipitation (bio12), the precipitation of the driest month (bio14), and precipitation seasonality (bio15). 
After that, we ran the MaxEnt model to assess the habitat suitability both at present and in 2050. During the model training process, random samples of 10,000 background points were used, which has been shown to perform similarly when compared to models using all potential background points [56]. To reduce overfitting, the regularization multiplier was set at 4 [63]. This parameter determines how strongly increases in model complexity are penalized during model optimization. Radosavljevic and Anderson (2014) [64] found that regularization multiplier values from 2.0 to 4.0 were generally appropriate to minimize overfitting. We created 10 random data partitions with $75 \%$ of the occurrence data for training and $25 \%$ for testing. Mean values of the 10 replicated runs were used to compare the habitat suitability between the present and 2050. The primary output of most SDMs was a continuous raster representing the probability of species occurrence. For most applications, it is often necessary to select a threshold to classify each pixel into 'suitable' or 'unsuitable' [65]. As one of the SDMs, MaxEnt software provided 11 conversion thresholds, including "fixed cumulative value 1", "Fixed cumulative value 5", "Fixed cumulative value 10", "Minimum training presence", "10 percentile training presence", "Equal training sensitivity and specificity", "Maximum training sensitivity plus specificity", "Equal test sensitivity and specificity", "Maximum test sensitivity plus specificity", "Balance training omission, predicted area and threshold value", and "Equate entropy of thresholded and original distributions". In order to be consistent with the classification of the 4th national survey report on giant pandas, we selected the minimum training presence logistic as our low threshold and the maximum test sensitivity plus specificity as our high threshold in order to separate the continuous outputs into three classes of habitat suitability, namely suitable, moderately suitable, and low suitability.

We then coupled the human disturbance with climate change to evaluate the integrated impacts on the giant panda habitat. Additionally, based on the present conservation network as well as our habitat suitability analysis, we made suggestions on habitat protection policies to mitigate the influence of climate change and on where to select priority areas for expanded reserves. Furthermore, we also used a geographical information system to verify our suggestions.

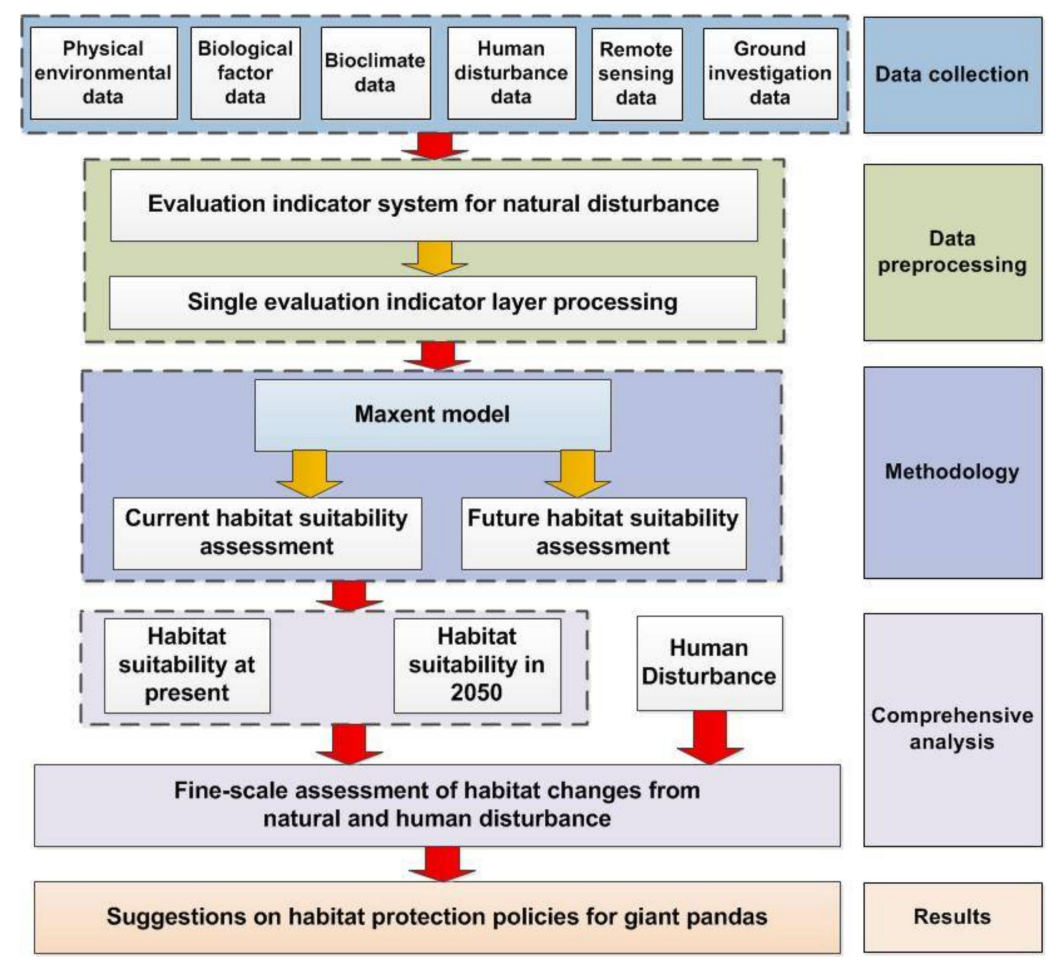

Figure 2. Flow chart of fine-scale climate change evaluation and countermeasures. 


\section{Results and Discussion}

\subsection{Habitat Suitability under Climate Change}

The habitat suitability index (HSI) map for the present and for 2050 was obtained by the average training AUC (0.74) and test AUC (0.72), indicating that the performance of the model was reliable (Figure 3). The three habitat suitability classes in the study area were divided by two thresholds, the minimum training presence logistic, and the maximum test sensitivity plus specificity. The areas of each class of habitat were $3038.00 \mathrm{~km}^{2}, 3922.00 \mathrm{~km}^{2}$, and $1515.00 \mathrm{~km}^{2}$, compared to $4057.00 \mathrm{~km}^{2}$, $3241.00 \mathrm{~km}^{2}$, and $1177.00 \mathrm{~km}^{2}$ in 2050 (Table 1). We can conclude that the suitable area for giant pandas is increasing by about $33.54 \%$ and the low suitability area is decreasing by about $22.31 \%$, and the increasing region is distributed in the north-west, north-east, and south-east of the study area. It should be noted that this result assumes change is driven only by climate change.

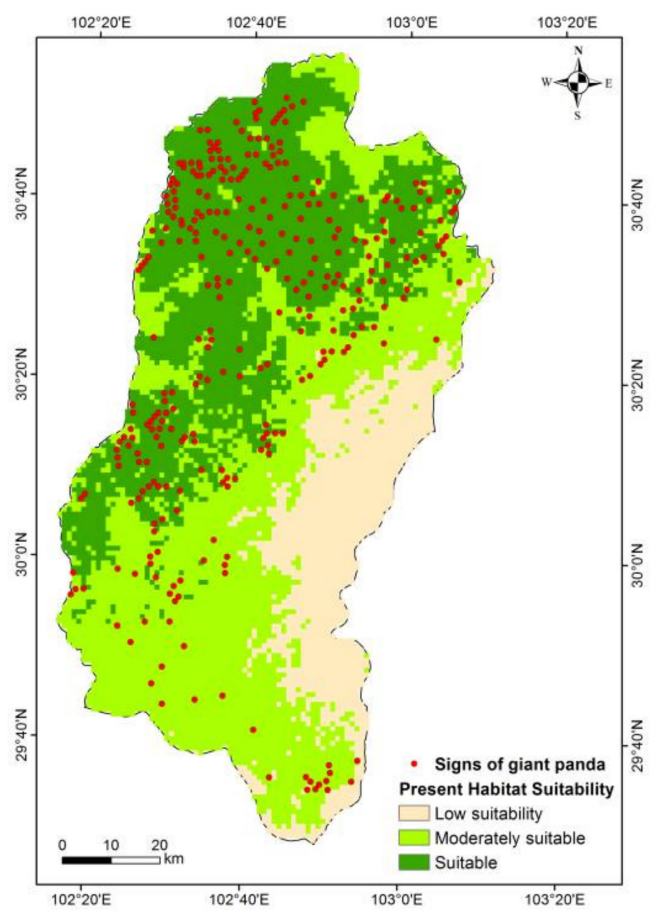

(a)

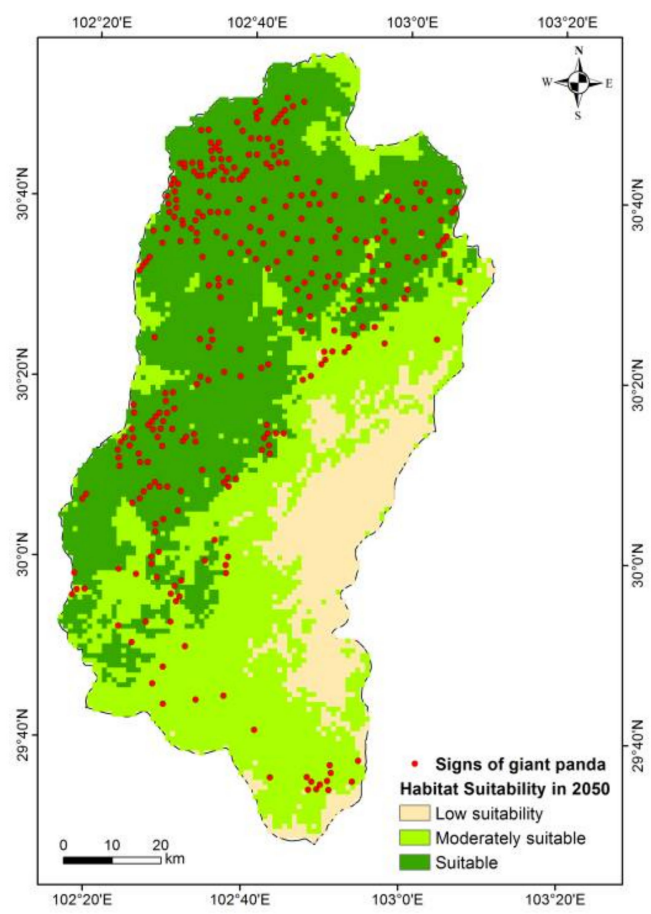

(b)

Figure 3. Giant panda habitat suitability (a) at present and (b) in 2050.

Table 1. Change in the suitability of giant panda habitats in the study area from the present to 2050.

\begin{tabular}{|c|c|c|c|}
\hline Habitat Type & $\begin{array}{c}\text { Suitable } \\
\left(\mathrm{km}^{2}\right)\end{array}$ & $\begin{array}{c}\text { Moderately Suitable } \\
\left(\mathrm{km}^{2}\right)\end{array}$ & $\begin{array}{c}\text { Low Suitability } \\
\left(\mathrm{km}^{2}\right)\end{array}$ \\
\hline Present & 3038.00 & 3922.00 & 1515.00 \\
\hline 2050 & 4057.00 & 3241.00 & 1177.00 \\
\hline Change & 1019.00 & -681.00 & -338.00 \\
\hline Change rate $(\%)$ & 33.54 & -17.36 & -22.31 \\
\hline
\end{tabular}

The possible causes of this change can be explained by the extent of the broad-leaved forest, coniferous and broad-leaved mixed forest, and coniferous forest caused by climate change.

Based on the analysis of 65 years (1951-2016) of continuous meteorological data, we can see that the annual average temperature increased at a rate of $0.114{ }^{\circ} \mathrm{C} /$ decade, and that the rate has accelerated since the 1990s. At the same time, we find that the temperature had a rapid shift in 1987, coinciding with the findings of Varotsos et al. (2014) [21]. The annual precipitation decreased slowly at a rate of 
$-33.22 \mathrm{~mm} /$ decade, showing a "warm-dry" trend. Within the 65 years, there were some precipitation anomalies, such as the anomalies in 1965/1966 and 1985/1986. According to Efstathiou et al. (2012), precipitation anomalies in the period 1900-2010 exhibited persistent, long-range correlations for all the time lags between 4 months and 28 years. This result states that the fluctuations of the precipitation anomalies in small time intervals are positively correlated to those in longer time intervals in what resembles a power law fashion [66]. Although temperature is a more important variable influencing giant panda habitats [29], we also should take into account the power law relation dictated by the observed precipitation data in precipitation forecasting and analysis in the future (see Figure 4).

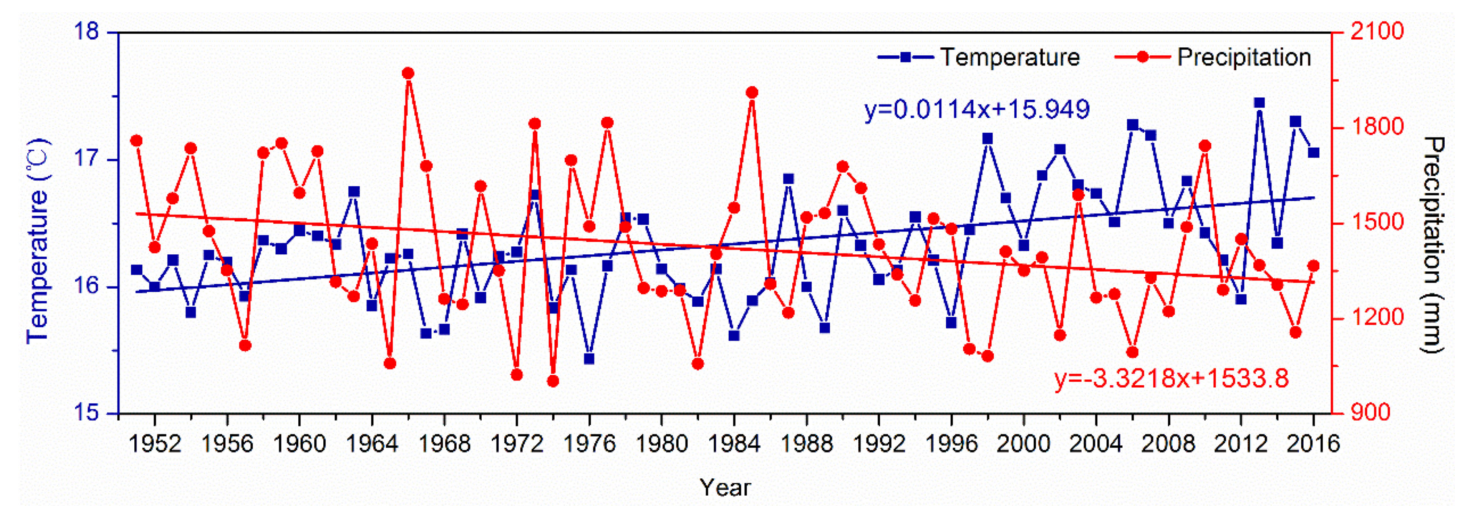

Figure 4. Temperature and precipitation data from 1951 to 2016.

At the same time, one study pointed out that the forest ecosystem will benefit from climate change. The natural ecological system in south-western China will be affected by climate change, with possible results including a change of ecological vegetation type, an increase in the elevation of the tree line, and shrub species invading the alpine meadow [5]. The largest vegetation type by area in the Sichuan giant panda habitat is broad-leaved forest, with a total area of 748,600 ha, followed by coniferous forest, at 703,000 ha. The two vegetation types accounted for $71.88 \%$ [24] of the total area of vegetation in the Sichuan giant panda habitat [33]. The research results of our team have shown that over the past 30 years, the vertical mountain zones have increased in the giant panda habitat of Wolong nature reserve [67]. This result is in accordance with the generally agreed range shifts trend, i.e., towards the poles or higher altitudes [4,6]. The research of Walther et al., (2002) showed that because of environmental warming, the treeline in Europe and New Zealand has shifted towards higher altitudes, and the alpine plants in the European Alps also show an elevational shift of $1-4 \mathrm{~m}$ per decade [68]. Therefore, with the warming climate, the tree line will rise, resulting in expanding broad-leaved forests, broad-leaved and coniferous mixed forests, and coniferous forests. As a result, the scope of the giant panda habitat will expand too. This may be one of the causes for the increase in overall potentially suitable habitats.

\subsection{Habitat Suitability Changes under Combined Climate Change and Human Disturbance}

In fact, 17 human disturbance factors were found during the fourth giant panda survey, influencing or aggravating the habitat of giant pandas. Road traffic (national road, provincial road and highway), hydroelectric stations, mines, scenic spots and power-transmission lines are five factors that occurred often within the study area. Therefore, these five human disturbance factors were selected in this paper. According to the fourth survey report, by comparing the number and density of signs of giant pandas near the different levels of roads we can draw the conclusion that highways have the most influence on the distribution of giant pandas. At the same time, there were no signs of giant pandas within $3 \mathrm{~km}$ of a highway. As for other kinds of roads, the number and density of signs of giant pandas will increase when the distance to roads is more than $2 \mathrm{~km}$. The other disturbance factors also showed a similar, regular distance pattern [33]. Consequently, the influence range was set to 
$3 \mathrm{~km}$ for highways and $2 \mathrm{~km}$ for other disturbance factors. Using overlay analysis and buffer analysis, the combined influence of human and climate change on giant panda habitat suitability was mapped (Figure 5). Habitat distribution mapping with comprehensive consideration of climate and human disturbance shows that the suitable and moderately suitable habitat areas will decrease about $58.56 \%$ and $62.29 \%$ compared to the result only considering the influence of climate change (Table 2).

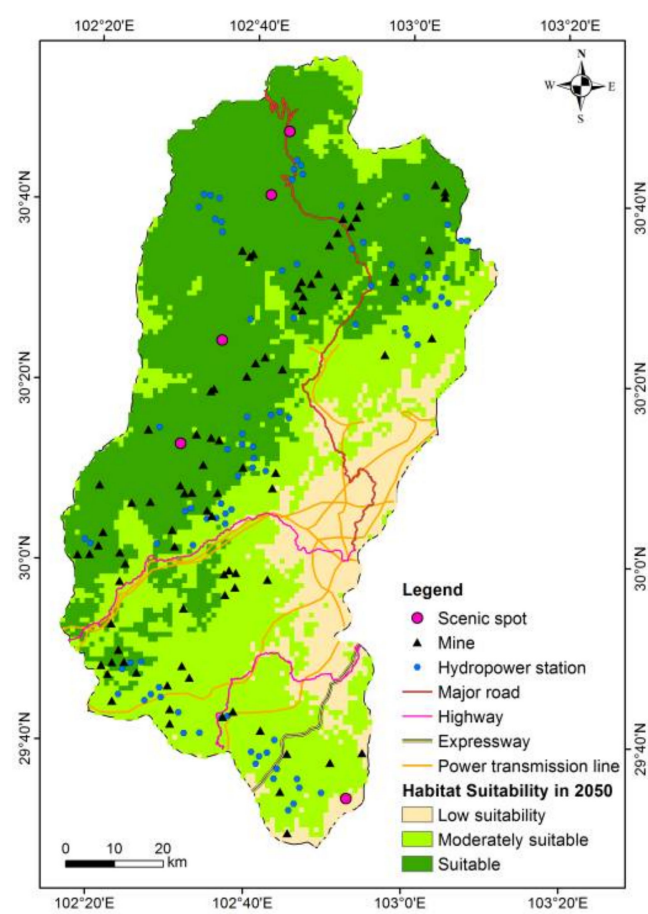

(a)

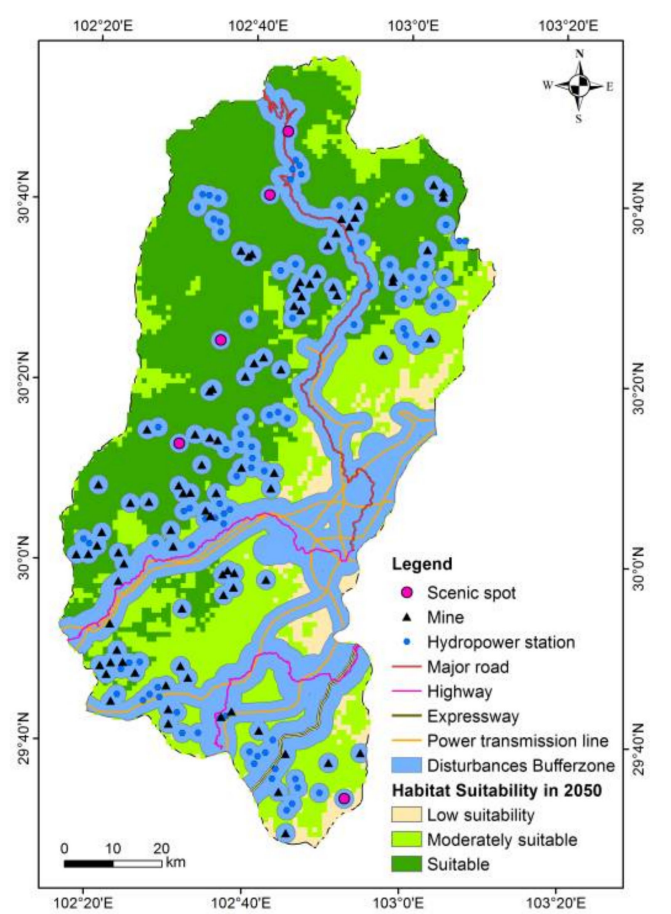

(b)

Figure 5. (a) Overlay analysis of human disturbance factors and (b) buffer analysis of human disturbance factors.

Table 2. Change in the suitability of giant panda habitats in the study area considering human disturbance factors in 2050 .

\begin{tabular}{ccc}
\hline Habitat Type & Suitable $\left.\mathbf{( k m}^{\mathbf{2}}\right)$ & Moderately Suitable $\mathbf{( k m}^{\mathbf{2}} \mathbf{~}$ \\
\hline Present & 3038.00 & 3922.00 \\
2050 & 4057.00 & 3241.00 \\
Buffer analysis of human disturbance & 1259.00 & 1479.00 \\
Change & -1779.00 & -2443.00 \\
Change rate $(\%)$ & -58.56 & -62.29 \\
\hline
\end{tabular}

In summary, the results showed the following: (1) only considering climate change, the suitable habitat will increase $1,019.00 \mathrm{~km}^{2}$ and the moderately suitable habitat and low suitability habitat will decrease by $681.00 \mathrm{~km}^{2}$ and $338.00 \mathrm{~km}^{2}$, respectively. That is to say, the overall habitat that can be used by giant pandas in this region will increase, which is different from most of the previous results showing a decrease. (2) The new suitable habitat will shift westward, northward and eastward in this region. This result is consistent with the trend of ground survey data between the fourth and third national giant panda surveys in China. (3) Conversely, the suitable habitat will be significantly reduced (about 58.56\%) and fragmentized when taking into account human disturbance factors such as roads, transmission lines, mining sites and hydropower stations. 


\subsection{Discussion}

This study tests the application of predictive modeling and mapping on giant panda habitats with the maximum entropy algorithm. Our results highlight the need for future efforts to conserve giant pandas with reserve planning, design of ecological corridors, and other science-based suggestions. More attention should be paid to areas in north-western, north-eastern, and south-western Ya'an. These regions were predicted to be the most suitable both currently and in the future. The reason for this is that climate change will cause timberline variation. Observation data from meteorological stations suggest that the annual temperature increased $0.114{ }^{\circ} \mathrm{C} /$ decade and annual precipitation decreased $-33.22 \mathrm{~mm} /$ decade in Ya'an from 1951 to 2016. Climate warming and drying drives the tree line upwards and shrubs invade alpine meadow vegetation. Our previous study found that rising temperatures will make timberline growth and broad-leaved forest, coniferous broad-leaved forest, and coniferous forest expansion obvious in the Wolong and Wanglang nature reserves in the next 30 years. Our results in this paper showed the habitat distribution will expand due to a warming climate, which is a similar conclusion with [29].

On the other hand, human activities play a negative role that cannot be ignored. The habitat area, patch number and biodiversity will be influenced by road traffic, hydroelectric stations, quarries, tourism, and power-transmission lines. For example, roads alter habitats and result in habitat loss and fragmentation, consequently reducing genetic exchange among populations. The Daxiangling nature reserve, located in the south of the study area, is cut apart by 108 national roads, with the giant panda population separated into Paocaowan, Xinmiao and Sanhe, three different small groups.

In summary, in order to effectively protect the iconic species of giant pandas, we need more accurate assessment results. Uncertainty is an important consideration for all climate change assessments [69]. The lack of high-resolution climatic data is one source of uncertainty that can substantially impact assessment findings. With the rapid development of remote-sensing technology, using contemporary remote-sensing data to enhance predictions at fine scales beyond climatic variables may be a possible direction [63].

\subsection{Suggestion}

Our study has several implications for managing the giant pandas and their threatened habitat. At present, there are only three nature reserves separately distributed in our study area, which is disadvantageous for communication between giant pandas within the Qionglai Mountains, as well as the stability and increase of the wild giant panda population. Therefore, the conservation network should be adjusted. Here we give some suggestions according to our research.

1. Based on the Fengtongzhai national nature reserve, we suggest expanding this nature reserve eastward. Under future climate change, there will be a large, new suitable habitat emerging in the north-west and east beside Fengtongzhai. Additionally, according to the fourth survey report, the giant panda habitat within this nature reserve has increased from 30,936 ha to 32,899 ha compared with the result of the third survey undertaken 10 years ago, a $6.35 \%$ increase. Hence, we suggest expanding the new reserve eastward based on the Fengtongzhai nature reserve (see Figure 6a, A; the total area of $A$ is $13,235 \mathrm{ha})$.

2. We suggest expanding new reserves in the west of the Labahe provincial nature reserve, which is connected from north to south and may cover the newly added suitable habitat. Our model showed that there will be a new, concentrated suitable habitat in the west and north-west side of Labahe provincial nature reserve in the future. At the same time, the fourth panda survey report showed that the number of wild giant pandas living in Labahe reserve has increased dramatically, from 11 during the third panda survey to 20 in the fourth panda survey, an increase of $81.82 \%$. Therefore, we suggest that we should pay more attention to the western side of this nature reserve and expand new reserves which must connect from north to south so as to include the new emerging suitable habitat (see Figure 6a, B; the total area is 50,992 ha). 
In order to further verify the possibility of our two suggested areas as a new, expanded reserve, we overlayed the A and B regions with GF-1 remote-sensing images acquired on 7 March 2017 (see Figure $6 \mathrm{~b}$ ), and DEM data(see Figure 6c). Through a comprehensive analysis, we found that the vegetation type in region A mainly included coniferous forest and conifer-broadleaved forest, which wild giant pandas find more favorable. Meanwhile, the elevation within region A is from $1026 \mathrm{~m}$ to $2348 \mathrm{~m}$, with a mean elevation of $1623 \mathrm{~m}$. Consequently, it is possible to turn region A into a new nature reserve. As for region B, this is located in the north-west of Labahe nature reserve, which is mainly covered by forest and grassland. The elevation within this area is between $1500 \mathrm{~m}$ to $3400 \mathrm{~m}$, where giant pandas can live. This area is seldom disturbed by humans at present; namely, there are no mines, no roads, no hydropower stations and so on. Thus, considering the accelerated rate of climate change, this area may be a good choice to convert into a new reserve.

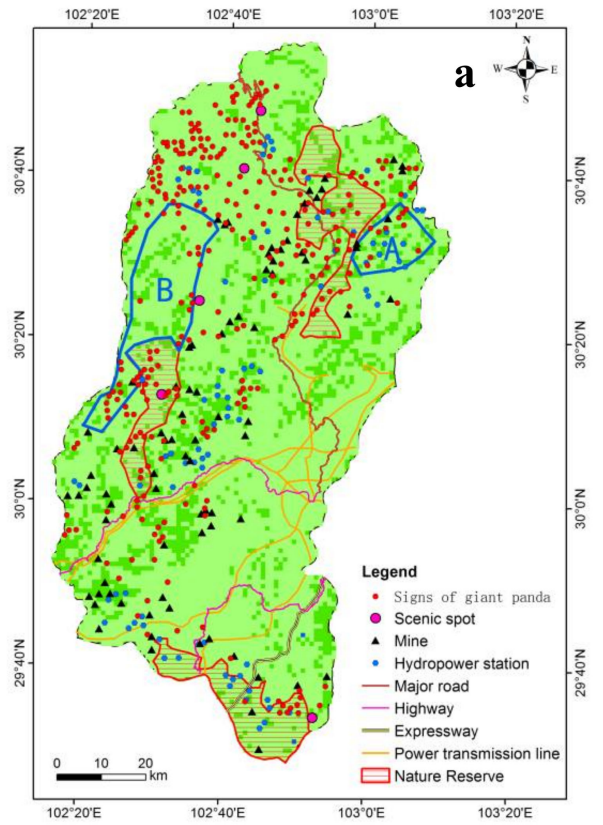

(a)

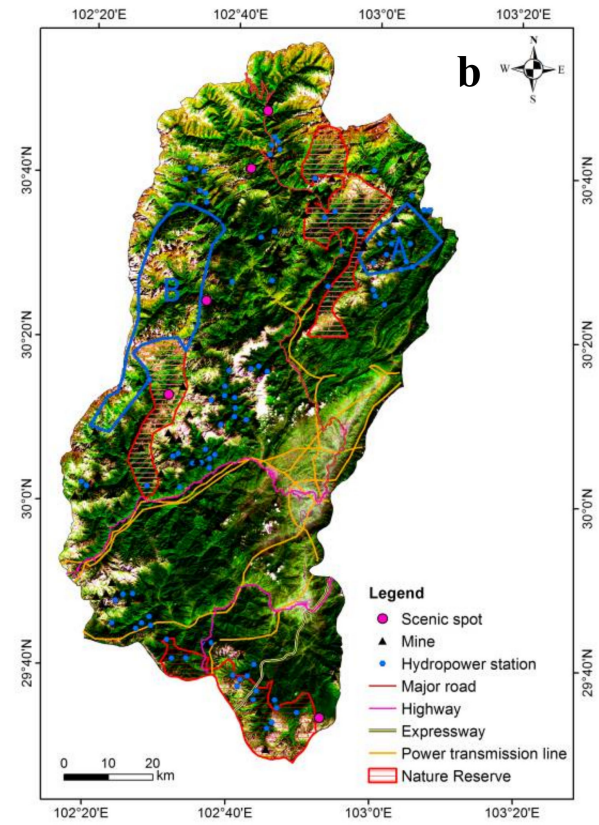

(b)

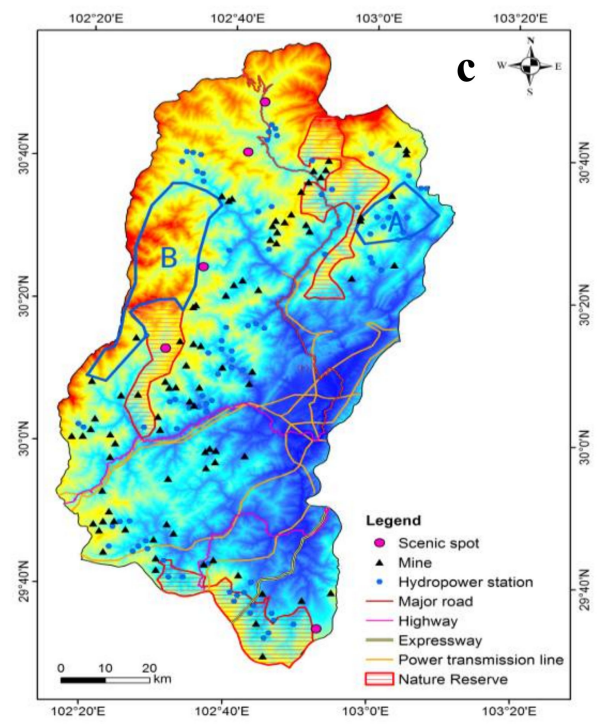

(c)

Figure 6. (a) Regions A and B are the two new suggested areas; (b) shows the suggested areas overlayed with GF-1 imagery; and (c) shows the suggested areas overlayed with a DEM. 
3. A translocation strategy can be taken into account for the Daxiangling nature reserve in the future. Our model predicted that there will be a large amount of habitat degradation in the Daxiangling nature reserve, located in Yingjing County in the south of our study area. This result is consistent with the research finding of Chenzhao et al. (2017) [30]. Daxiangling Mountain holds the smallest giant panda population and habitat area before the modification of the separation line with Qionglai Mountain. The third survey report showed that there are 16 giant pandas living in this mountain area. As for the Daxiangling nature reserve, there are only seven giant pandas living there, according to the fourth survey result. At the same time, the very important corridor of Nibashan crosses the majority of the Daxiangling nature reserve, which is the key area linking the Xinmiao, Sanhe and Paocaowan local giant panda groups. Unfortunately, there are many human disturbances within this area, such as national highway 108 from Yingjing to Hanyuan and highway G5 from Ya'an to Xichang, which pass through this area. Also, many hydropower stations and mines are located within this region. In summary, the giant panda habitat within this area will experience more degradation and fragmentation in the near future, and the giant pandas that live here face severe survival challenges. Considering this situation, if it is hard to change and improve the living conditions, we suggest translocation as a potential option. Translocation is a tool that may be useful in adaptation strategies if habitat losses in the south become severe enough to warrant moving small populations to areas where they have a better chance of survival. One giant panda needs at least 400 ha [16] to sustain it, according to previous research. Based on our research, there are, in total, 64,227 ha in the two new suggested regions, which is enough to hold the panda populations that inhabit Daxiangling nature reserve. Through this method, we can also help bolster other populations against the risk of extinction [24].

4. Before the year 2050, the risk of food shortage persists because the bamboo may bloom within a large area during a short period of time. The giant panda is a specialized diet animal, as bamboo constitutes $99 \%$ of its diet. In Sichuan province, there are seven genera and 32 species of bamboo that can serve as the food of giant pandas, with a distribution area of 192.55 million ha, accounting for $94.88 \%$ of the total area of the panda habitat in the province. Among them, the largest distribution area is that of arrow bamboo, followed by the presence of Fargesia denudata, Yushania brevipaniculata and Chimonobambusa szechuanensis. According to the historical record of bamboo flowering in Sichuan Province, we found that the four counties within our study area, namely, Tianquan, Baoxing, Lushan, and Yingjing, most recently experienced large bamboo blooms and die-offs during the period from the middle of the 1970s to the middle of the 1980s. Meanwhile, on the basis of historical literature and interviews with local elders, we know that the cycle of bamboo blooms can be categorized into three types: 50 years, 60 years, and 90-100 years. In addition, the well-established quasi 60-year natural cycle, the most prominent climate variability component of global and Northern Hemisphere annual mean temperature [21], should also be considered. Hence, if we calculate with a 60-year cycle, there will be a new round of bamboo flowering during the 2040s. At the same time, there are studies showing that warmer climate change may lead to plant phenological phasing ahead of time. Therefore, in order to alleviate the negative influence of bamboo flowering, bamboo rejuvenation and species richness should be taken into account in the future.

\section{Conclusions}

Climate change is only one of a long list of pressures that influence the distributions and health of species populations. At the same time, human disturbance is known to intensify the negative impacts of climate change through habitat loss and fragmentation. Through a fine-scale evaluation of the core area of the Sichuan Giant Panda Sanctuaries UNESCO World Natural Heritage site, we can draw some conclusions as follows.

First, the overall suitability of giant panda habitats remains a major concern. Over the past decades, the Chinese government has implemented many conservation programs to protect giant pandas, such as the Grain-to-Green program, the Natural Forest Protection Project, and the establishment of 
a series of reserves. Consequently, the population of giant pandas has increased from 1114 to 1864 (State Forestry Administration, 2015), and the species has been downlisted from "Endangered" to "Vulnerable" in the IUCN Red List of Threatened Species [70]. Against the background of effective protection, the population and density of giant pandas inhabiting Ya'an prefecture both increased [33]. When simply considering climate change, the giant panda habitat in Ya'an prefecture will increase. However, while incorporating the current conservation network, as well as human disturbance, suitable habitat will decrease and become more fragmented by roads, power-transmission lines, and so on. Hence, the situation of giant panda conservation in Ya'an Prefecture is still challenging.

Second, the existing conservation network in the study area is not yet sufficient, although a number of protective measures have been implemented to protect the giant pandas, such as returning the grain plots to forestry, natural forest-conservation projects [71] and creating nature reserves. To date, there are 67 nature reserves that have been established in China to protect the giant panda and sympatric distributed species which cover $58 \%$ of its habitat (1.4 million ha) [10]. However, from the perspective of this study area, the existing conservation network is still not adequate. This study area spanned the core remaining ranges of giant panda habitats, but only contained Fengtongzhai National Nature Reserve as well as the Labahe and Daxiangling provincial nature reserves, which are all very small and far from each other. This situation is detrimental to the current population stability, gene exchange, and effective conservation of giant panda habitats. Even worse is that this conservation network cannot effectively protect giant pandas currently, nor can it protect new emerging potential giant panda habitats in the future.

Third, it is necessary to adjust the conservation network, even considering translocation measures. Fengtongzhai National Nature Reserve, which lies in the north of study area, can be expanded about 13,235 ha to the east (suggested region A). Labahe provincial nature reserve can be expanded about 50,992 ha north-westward by creating an associated conservation area from north to south (suggested region $B$ ) to cover the new emerging suitable habitat under the consequences of climate change. Daxiangling provincial nature reserve, which is located in the south of our study area, can be taken into account via translocation measures because there will be large areas of habitat degradation and serious habitat fragmentation caused by human activity and climate change in the future.

In summary, our research findings can help improve protected area designations, prioritize conservation regions, and aid in corridor designations, therefore improving the effectiveness of conservation in the current giant panda protection network. However, under dry and warm climate stress, giant pandas compelled to disperse to new habitats may be influenced by many natural and artificial factors such as geographical barriers, ecological corridors, human disturbances, and reserve planning. These influences require further in-depth study.

Acknowledgments: This work was financially supported by the National Key Research and Development Program of China (No. 2016YFC0503302), the International S\&T Cooperation program (No. 2013DFG21640), the Science and Technology Service Network Initiative (No. KFJ-SW-STS-181), and the Natural Science Foundation of Qinghai Province (No. 2017-ZJ-926Q). We are thankful for the dedicated support of Guojin He, Yinghua Li, Weili Jiao and Bo Cheng for our research. We are grateful for the help of Lili, Ning Nie, Huichan Liu, Xiaomei Zhang, Guizhou Wang and senior student Ziwei Li and Yuanhe Li of Beijing University of Civil Engineering and Architecture in the data processing, We also thank Fernando Manoel Ramos and Aline Soterroni at the National Institute for Space Research of Brazil (INPE) for their advice about the research method. We thank all of the people who conducted field work for this project, especially senior researcher Lianjun Zhao and Zhengbin Tu of Wanglang nature reserve. Among a number of colleagues and others whose thoughts and suggestions have helped to improve this paper considerably from earlier versions, in particular, we wish to acknowledge the contributions of Qunli Han, Yunwei Tang and Yanchuang Zhao. The authors would also like to thank the anonymous reviewers for their helpful suggestions.

Author Contributions: Jing Zhen and Xinyuan Wang conceived and designed the study; Jing Zhen, Xinyuan Wang, Qingkai Meng and Lei Luo performed the experiment and wrote the paper; Jing Zhen, Qingkai Meng, Jingwei Song, Ying Liao, Bo Xiang, Huadong Guo, Chuansheng Liu and Ruixia Yang contributed to data collection and processing.

Conflicts of Interest: The authors declare no conflict of interest. 


\section{References}

1. Intergovernmental Panel on Climate Change (IPCC). Climate Change 2014: Synthesis Report; IPCC: Geneva, Switzerland, 2014.

2. Fan, J.; Li, J.; Xia, R.; Hu, L.; Wu, X.; Li, G. Assessing the impact of climate change on the habitat distribution of the giant panda in the qinling mountains of China. Ecol. Model. 2014, 274, 12-20. [CrossRef]

3. Qin, A.; Liu, B.; Guo, Q.; Bussmann, R.W.; Ma, F.; Jian, Z.; Xu, G.; Pei, S. Maxent modeling for predicting impacts of climate change on the potential distribution of thuja sutchuenensis franch, an extremely endangered conifer from southwestern China. Glob. Ecol. Conserv. 2017, 10, 139-146. [CrossRef]

4. Parmesan, C.; Yohe, G. A globally coherent fingerprint of climate change impacts across natural systems. Nature 2003, 421, 37-42. [CrossRef] [PubMed]

5. Compilation Committee of the third national assessment report on climate change. The Third National Assessment Report on Climate Change; Science Press: Beijing, China, 2015. (In Chinese)

6. Root, T.L.; Price, J.T.; Hall, K.R.; Schneider, S.H.; Rosenzweig, C.; Pounds, J.A. Fingerprints of global warming on wild animals and plants. Nature 2003, 421,57-60. [CrossRef] [PubMed]

7. Li, R.Q.; Xu, M.; Wong, M.H.G.; Qiu, S.; Li, X.H.; Ehrenfeld, D.; Li, D.M. Climate change threatens giant panda protection in the 21st century. Biol. Conserv. 2015, 182, 93-101. [CrossRef]

8. Urban, M.C. Accelerating extinction risk from climate change. Science 2015, 348, 571-573. [CrossRef] [PubMed]

9. Xu, W.; Viña, A.; Kong, L.; Pimm, S.L.; Zhang, J.; Yang, W.; Xiao, Y.; Zhang, L.; Chen, X.; Liu, J. Reassessing the conservation status of the giant panda using remote sensing. Nat. Ecol. Evol. 2017, 1, 1635-1638. [CrossRef] [PubMed]

10. Wei, F.W.; Swaisgood, R.; Hu, Y.B.; Nie, Y.G.; Yan, L.; Zhang, Z.J.; Qi, D.W.; Zhu, L.F. Progress in the ecology and conservation of giant pandas. Conserv. Biol. 2015, 29, 1497-1507. [CrossRef] [PubMed]

11. State Forestry Administration. The Third National Survey Report on Giant Panda in China, 1st ed.; Science Press: Beijing, China, 2006. (In Chinese)

12. Hu, J.C.; Zhang, Z.J.; Wei, F.W. History, current situation and prospects on nature reserves for giant pandas (Ailuropoda melanoleuca) in China. Acta Theriol. Sin. 2011, 31, 10-14.

13. Zhu, L.; Hu, Y.; Zhang, Z.; Wei, F. Effect of China's rapid development on its iconic giant panda. Chin. Sci. Bull. 2013, 58, 2134-2139. [CrossRef]

14. Harald, P.; Michael, G.; Karl, R.; Christian, K.; Georg, G. Signals of range expansions and contractions of vascular plants in the high alps: Observations (1994-2004) at the gloria * master site schrankogel, tyrol, austria. Glob. Chang. Biol. 2007, 13, 147-156.

15. Wang, L.-E.; Zeng, Y.; Zhong, L. Impact of climate change on tourism on the qinghai-tibetan plateau: Research based on a literature review. Sustainability 2017, 9, 1539. [CrossRef]

16. Shen, G.Z.; Pimm, S.L.; Feng, C.Y.; Ren, G.F.; Liu, Y.P.; Xu, W.T.; Li, J.Q.; Si, X.F.; Xie, Z.Q. Climate change challenges the current conservation strategy for the giant panda. Biol. Conserv. 2015, 190, 43-50. [CrossRef]

17. Liu, J.; Ouyang, Z.; Taylor, W.W.; Groop, R.; Tan, Y.; Zhang, H. A framework for evaluating the effects of human factors on wildlife habitat: The case of giant pandas. Conserv. Biol. 1999, 13, 1360-1370. [CrossRef]

18. O'Brien, S.J.; Pan, W.; Lu, Z. Pandas, people and policy. Nature 1994, 369, 179-180. [CrossRef] [PubMed]

19. State Council Information Office of China. 2015. Available online: Http://www.Scio.Gov.Cn/xwfbh/ gbwxwfbh/fbh/document/1395514/1395514.Htm (accessed on 9 March 2017).

20. Kang, D.W.; Wang, X.R.; Yang, H.W.; Duan, L.J.; Li, J.Q. Habitat use by giant panda in relation to man-made forest in wanglang nature reserve of China. Environ. Sci. Pollut. Res. 2014, 21, 13440-13445. [CrossRef] [PubMed]

21. Varotsos, C.A.; Franzke, C.L.E.; Efstathiou, M.N.; Degermendzhi, A.G. Evidence for two abrupt warming events of sst in the last century. Theor. Appl. Climatol. 2014, 116, 51-60. [CrossRef]

22. Lin, Z.S.; Xian, S. Multi-scale analysis of global temperature changes and trend of a drop in temperature in the next 20 years. Meteorol. Atmos. Phys. 2007, 95, 115-121.

23. Hu, J. The most affairs of giant panda. Wild Anim. 1984, 4, 1-5. (In Chinese)

24. Songer, M.; Delion, M.; Biggs, A.; Huang, Q. Modeling impacts of climate change on giant panda habitat. Int. J. Ecol. 2012, 2012, 1-12. [CrossRef] 
25. Jian, J.; Jiang, H.; Jiang, Z.S.; Zhou, G.M.; Yu, S.Q.; Peng, S.L.; Liu, S.R.; Liu, S.Y.; Wang, J.X. Predicting giant panda habitat with climate data and calculated habitat suitability index (HSI) map. Meteorol. Appl. 2014, 21, 210-217. [CrossRef]

26. Gong, M.; Guan, T.; Hou, M.; Liu, G.; Zhou, T. Hopes and challenges for giant panda conservation under climate change in the qinling mountains of China. Ecol. Evol. 2017, 7, 596-605. [CrossRef] [PubMed]

27. Li, J.; Liu, F.; Xue, Y.D.; Zhang, Y.; Li, D.Q. Assessing vulnerability of giant pandas to climate change in the qinling mountains of China. Ecol. Evol. 2017, 7, 4003-4015. [CrossRef] [PubMed]

28. Tuanmu, M.-N.; Vina, A.; Winkler, J.A.; Li, Y.; Xu, W.; Ouyang, Z.; Liu, J. Climate-change impacts on understorey bamboo species and giant pandas in China's Qinling mountains. Nat. Clim. Chang. 2013, 3, 249-253. [CrossRef]

29. Liu, G.; Guan, T.P.; Dai, Q.; Li, H.X.; Gong, M.H. Impacts of temperature on giant panda habitat in the north Minshan mountains. Ecol. Evol. 2016, 6, 987-996. [CrossRef] [PubMed]

30. Zhao, C.; Yue, B.; Ran, J.; Timothy, M.; Hou, N.; Yang, X.; Gu, X. Relationship between human disturbance and endangered giant panda Ailuropoda melanoleuca habitat use in the Daxiangling mountains. Oryx 2016, 51, 146-152. [CrossRef]

31. Song, J.W.; Wang, X.Y.; Liao, Y.; Zhen, J.; Ishwaran, N.; Guo, H.D.; Yang, R.X.; Liu, C.S.; Chang, C.; Zong, X. An improved neural network for regional giant panda habitat suitability mapping: A case study in Ya'an prefecture. Sustainability 2014, 6, 4059-4076. [CrossRef]

32. World Wide Fund For Nature (WWF). History of the Giant Panda. 2004. Available online: http:/ /wwf. panda.org/?13588/History-of-the-Giant-Panda (accessed on 10 May 2017).

33. Sichuan Province Forestry Administration. The 4th Survey Report on Giant Panda in Sichuan Province; Sichuan Science Press: Chengdu, China, 2015. (In Chinese)

34. Ouyang, Z.; Liu, J.; Xiao, H.; Tan, Y.C.; Zhang, H.M. An assessment of giant panda habitat in wolong nature reserve. Acta Ecol. Sin. 2001, 21, 1869-1874.

35. Zhou, J. The Study on the Quality Evaluation System of Giant Panda Habitat. Ph.D. Thesis, Beijing Forestry University, Beijing, China, 2008. (In Chinese)

36. Ouyang, Z.; Liu, J.; Zhang, H. Community structure analysis of giant panda habitat in Wolong. Acta Ecol. Sin. 2000, 20, 458-462.

37. Zhang, W.; Tang, Z.; Dunwu, Q.I.; Yuanman, H.U.; Jinchu, H.U.; Dan, B. Comparison of two evaluation methods on wild animal habitat suitability: A case study of Ailuropoda melanoleuca in Daxiangling mountains. Chin. J. Ecol. 2006, 25, 1465-1469.

38. Hull, V.; Zhang, J.D.; Huang, J.Y.; Zhou, S.Q.; Vina, A.; Shortridge, A.; Li, R.G.; Liu, D.A.; Xu, W.H.; Ouyang, Z.Y.; et al. Habitat use and selection by giant pandas. PLoS ONE 2016, 11, e0162266. [CrossRef] [PubMed]

39. Zhao, S.; Zheng, P.; Dong, S.; Zhan, X.; Wu, Q.; Guo, X.; Hu, Y.; He, W.; Zhang, S.; Fan, W. Whole-genome sequencing of giant pandas provides insights into demographic history and local adaptation. Nat. Genet. 2013, 45, 67. [CrossRef] [PubMed]

40. Dierenfeld, E.S.; Qiu, X.; Mainka, S.A.; Liu, W.X. Giant panda diets fed in five chinese facilities: An assessment. Zoo Biol. 1995, 14, 211-222. [CrossRef]

41. Hu, J.; Deng, Q.; Yu, Z.; Zhou, S.; Tian, Z. Ecology and biology research on giant panda, golden monkey and other rare animals. J. Nanchong Norm. Univ. Nat. Sci. Ed. 1980, 2, 1-39+127-134. (In Chinese)

42. Schipper, J.; Chanson, J.S.; Chiozza, F.; Cox, N.A.; Hoffmann, M.; Katariya, V.; Lamoreux, J.; Rodrigues, A.S.; Stuart, S.N.; Temple, H.J. The status of the world's land and marine mammals: Diversity, threat, and knowledge. Science 2008, 322, 225. [CrossRef] [PubMed]

43. Hu, J.C. Giant panda's change during recent 40 years. J. Sichuan Teach. Coll. Nat. Sci. 1993, 14, 99-103.

44. Qi, D.; Hu, Y.; Gu, X.; Yang, X.; Yang, G.; Wei, F. Quantifying landscape linkages among giant panda subpopulations in regional scale conservation. Integr. Zool. 2012, 7, 165-174. [CrossRef] [PubMed]

45. Carr, L.W.; Fahrig, L.; Pope, S.E. Impacts of Landscape Transformation by Roads. In Applying Landscape Ecology in Biological Conservation; Springer: New York, NY, USA, 2002; pp. 225-243.

46. Hijmans, R.J.; Cameron, S.E.; Parra, J.L.; Jones, P.G.; Jarvis, A. Very high resolution interpolated climate surfaces for global land areas. Int. J. Climatol. 2005, 25, 1965-1978. [CrossRef]

47. Xin, X.; Wu, T.-W.; Zhang, J. Introduction of CMIP5 experiments carried out with the climate system models of beijing climate center. Adv. Clim. Chang. Res. 2013, 4, 41-49. [CrossRef] 
48. Hibbard, K.A. The next generation of scenarios for climate change research and assessment. Nature 2010, $463,747-756$.

49. Meng, Q.K.; Miao, F.; Zhen, J.; Wang, X.Y.; Wang, A.; Peng, Y.; Fan, Q. Gis-based landslide susceptibility mapping with logistic regression, analytical hierarchy process, and combined fuzzy and support vector machine methods: A case study from wolong giant panda natural reserve, China. Bull. Eng. Geol. Environ. 2016, 75, 923-944. [CrossRef]

50. Meng, Q.K.; Miao, F.; Zhen, J.; Huang, Y.; Wang, X.Y.; Peng, Y. Impact of earthquake-induced landslide on the habitat suitability of giant Panda in Wolong, China. J. Mt. Sci. 2016, 13, 1789-1805. [CrossRef]

51. Tang, Y.W.; Jing, L.H.; Li, H.; Liu, Q.J.; Yan, Q.; Li, X.X. Bamboo classification using worldview-2 imagery of giant panda habitat in a large shaded area in Wolong, Sichuan province, China. Sensors 2016, $16,1957$. [CrossRef] [PubMed]

52. Raxworthy, C.J.; Martinez-Meyer, E.; Horning, N.; Nussbaum, R.A.; Schneider, G.E.; Ortega-Huerta, M.A.; Peterson, A.T. Predicting distributions of known and unknown reptile species in madagascar. Nature 2003, 426, 837. [CrossRef] [PubMed]

53. Anderson, R.P.; Martinez-Meyer, E. Modeling species' geographic distributions for preliminary conservation assessments: An implementation with the spiny pocket mice (heteromys) of ecuador. Biol. Conserv. 2004, 116, 167-179. [CrossRef]

54. Phillips, S.J.; Anderson, R.P.; Schapire, R.E. Maximum entropy modeling of species geographic distributions. Ecol. Model. 2006, 190, 231-259. [CrossRef]

55. Elith, J.; Graham, C.H.; Anderson, R.P.; Dudík, M.; Ferrier, S.; Guisan, A.; Hijmans, R.J.; Huettmann, F.; Leathwick, J.R.; Lehmann, A. Novel methods improve prediction of species' distributions from occurrence data. Ecography 2006, 29, 129-151. [CrossRef]

56. Phillips, S.J.; Dudík, M. Modeling of species distributions with maxent: New extensions and a comprehensive evaluation. Ecography 2008, 31, 161-175. [CrossRef]

57. Elith, J.; Phillips, S.J.; Hastie, T.; Dudík, M.; Chee, Y.E.; Yates, C.J. A statistical explanation of maxent for ecologists. Divers. Distrib. 2011, 17, 43-57. [CrossRef]

58. Barrett, M.A.; Brown, J.L.; Junge, R.E.; Yoder, A.D. Climate change, predictive modeling and lemur health: Assessing impacts of changing climate on health and conservation in madagascar. Biol. Conserv. 2013, 157, 409-422. [CrossRef]

59. Yackulic, C.B.; Chandler, R.; Zipkin, E.F.; Royle, J.A.; Nichols, J.D.; Grant, E.H.C.; Veran, S. Presence-only modelling using maxent: When can we trust the inferences? Methods Ecol. Evol. 2013, 4, 236-243. [CrossRef]

60. Warren, D.L.; Seifert, S.N. Ecological niche modeling in maxent: The importance of model complexity and the performance of model selection criteria. Ecol. Appl. 2011, 21, 335-342. [CrossRef] [PubMed]

61. Swets, J.A. Measuring the accuracy of diagnostic systems. Science 1988, 240, 1285. [CrossRef] [PubMed]

62. Tanner, E.P.; Papes, M.; Elmore, R.D.; Fuhlendorf, S.D.; Davis, C.A. Incorporating abundance information and guiding variable selection for climate-based ensemble forecasting of species' distributional shifts. PLoS ONE 2017, 12, e0184316. [CrossRef] [PubMed]

63. Truong, T.T.A.; Hardy, G.E.S.; Andrew, M.E. Contemporary remotely sensed data products refine invasive plants risk mapping in data poor regions. Front. Plant Sci. 2017, 8. [CrossRef] [PubMed]

64. Radosavljevic, A.; Anderson, R.P. Making better m axent models of species distributions: Complexity, overfitting and evaluation. J. Biogeogr. 2014, 41, 629-643. [CrossRef]

65. Bean, W.T.; Brashares, J.S. The effects of small sample size and sample bias on threshold selection and accuracy assessment of species distribution models. Ecography 2012, 35, 250-258. [CrossRef]

66. Efstathiou, M.N.; Varotsos, C.A. Intrinsic properties of sahel precipitation anomalies and rainfall. Theor. Appl. Climatol. 2012, 109, 627-633. [CrossRef]

67. Chang, C.; Wang, X.; Yang, R.; Liu, C.; Luo, L.; Zhen, J.; Xiang, B.; Song, J.; Liao, Y. A quantitative characterization method for alpine vegetation zone based on dem and ndvi. Geogr. Res. 2015, 34, $2113-2123$.

68. Walther, G.R.; Post, E.; Convey, P.; Menzel, A.; Parmesan, C.; Beebee, T.J.; Fromentin, J.M.; Hoegh-Guldberg, O.; Bairlein, F. Ecological responses to recent climate change. Nature 2002, 416, $389-395$. [CrossRef] [PubMed]

69. Tang, Y.; Winkler, J.A.; Vina, A.; Liu, J.G.; Zhang, Y.B.; Zhang, X.F.; Li, X.H.; Wang, F.; Zhang, J.D.; Zhao, Z.Q. Uncertainty of future projections of species distributions in mountainous regions. PLOS ONE 2018, 13, e0189496. [CrossRef] [PubMed] 
70. Swaisgood, R.; Wang, D.; Wei, F. Ailuropoda Melanoleuca. Available online: http:/ / www.iucnredlist.org/ details /712/0 (accessed on 4 April 2017).

71. Li, Y.; Vina, A.; Yang, W.; Chen, X.; Zhang, J.; Ouyang, Z.; Liang, Z.; Liu, J. Effects of conservation policies on forest cover change in giant panda habitat regions, China. Land Use Policy 2013, 33, 42-53. [CrossRef] [PubMed] 